\title{
Research on Influence of Milling Parameters on Machining Deformation of Rectangular Thin- Walled Parts
}

\author{
Jing $\mathrm{Li}^{1}$, Ping $\mathrm{Xi}^{1}$ and Yang Jiao ${ }^{2, *}$ \\ ${ }^{1}$ School of Mechatronic Engineering Changchun University of Technology, Changchun 130012,China \\ ${ }^{2}$ Aviation University of Air-force, Changchun 130022, China \\ *Corresponding author
}

\begin{abstract}
Aiming at the problem that the machining accuracy of rectangular thin-walled parts are difficult to ensure because of poor rigidity and machining deformation which is easy to produce extremely, it used the three-dimensional finite element method and did analysis and calculation of rectangular thin-walled parts under the action of milling force. It obtained the machining deformation law and the changing trend of the machining deformation of rectangular thin-walled parts with milling parameters in the different milling parameters circumstance by adjusting the milling parameters(milling depth, milling width, feed rate). It provided the theoretical basis for the selection and optimization of thin-walled parts milling parameters in the actual milling process.
\end{abstract}

Keywords-milling; parameters; thin-walled parts; milling; deformation; finite element analysis

\section{INTRODUCTION}

Thin-walled parts are widely used in the stratosphere such as aviation and military. But it is easy to produce "let knife phenomenon" because of milling force during the machining process. It can lead upper thick, lower thin, size difference and poor manufacturability. Seriously the parts will be scrapped[1]. The milling force is mainly connected with milling parameters(milling depth, milling width, feed rate) in the actual milling process. So it is significant to study the influence of milling parameters on the deformation of thin-walled parts.

Many experts and scholars have carried out a lot of research on the prediction of thin-walled parts deformation. Guo Hun, et al. have analysed and calculated on the machining deformation of aviation thin-walled frame parts under the action of milling force and initial stress field. They obtained the law of the machining deformation[2]. Bi Yunbo, Ke Yinglin, Dong Huiyue et al. have carried out the finite element simulation of the machining deformation of aviation aluminum alloy thin-walled parts[2]. Wu Hongbing, Ke Yinglin, et al. have studied the machining deformation of the whole structure parts of the aviation frame[3]. Huang Zhigang et al. have researched on the orthogonal cutting to the prediction of thin-walled parts machining deformation[4]. Qin Guohua et al. have used the neural network method to predict the machining deformation of thin-walled parts[5].

At present the research on the influence trend of the milling parameters on the deformation of thin-walled parts is less. So in order to study the influence of milling parameters on thin-walled parts deformation trend, this paper is established thin-walled rectangular finite element model to study with the help of the software ABAQUS and eventually through experiment verified the correction of deformation trend.

\section{Key TECHNOLOGY OF Finite ELEMENT ANALYSIS OF MACHINING DEFORMATION OF THIN-WALLED PARTS}

\section{A. Geometry Modeling}

The part geometric model is shown in Figure I, $100 \mathrm{~mm}$ long, $30 \mathrm{~mm}$ high, and the thickness is $5 \mathrm{~mm}$. The three-dimensional modeling of rectangular thin-walled parts is simple, so according to the actual milling and the size of the part directly established the 3D model of rectangular thin-walled part at both ends of the unconstrained, at the bottom of the fixed constraint in the finite element analysis software ABAQUS.

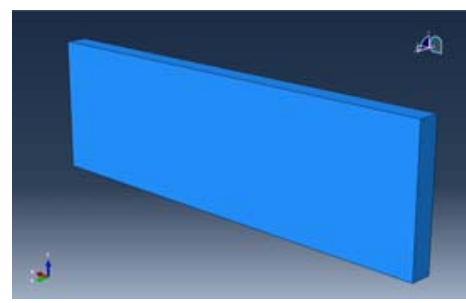

FIGURE I. PART GEOMETRIC MODEL

\section{B. Selection of the Part Material Model}

The form of Johnson-Cook constitutive equation is simple. It can solve the problem of high strain rate, high temperature and high temperature deformation in the process of metal material machining. It can truly reflect the flow stress of constitutive behavior of materials under high strain rate, high temperature and large strain. it has been widely used in thermal coupled analysis, especially in the instantaneous dynamic simulation[6]. Therefore Johnson-Cook model is widely used in the process of milling simulation. The expression of the Johnson-Cook constitutive model is:

$$
\sigma=\left[A+B \varepsilon^{n}\right]\left[1+C \operatorname{Cn}\left(\frac{\dot{\varepsilon}}{\dot{\varepsilon}_{0}}\right)\right]\left[1-\left(\frac{T-T_{0}}{T_{\text {melt }}-T_{0}}\right)^{m}\right]
$$

$\sigma$ _yield stress value of non zero strain rate, $\varepsilon$ —strain, 
$\dot{\varepsilon}_{0}$ _reference strain rate, it is $1 \mathrm{~s}-1, T_{0}$ _reference room temperature, $T_{\text {melt }}$-melting point temperature. $\mathrm{A}$ is yield strength of materials $(\mathrm{Pa}) . \mathrm{B}$ is material hardening modulus (Pa). $\mathrm{N}$ is strain strength coefficient. $\mathrm{C}$ is strain rate strength coefficient. $\mathrm{M}$ is thermal softening coefficient.

\section{Mesh Division of Part Geometric Model}

At present the finite element mesh division has three main methods:

- $\quad$ Lagrange method: In this method, the divided mesh is "pasted" on the material with the material flow.

- Euler method: In this method the mesh is fixed from start to finish, and the flow of the material is in the mesh[7].

- Improved Lagrange method: This method not only avoids the mesh large distortion but also improvs the mesh quality of large deformation problem. And it is significance to shorten the time of simulation and save the computer storage.

In this paper when used ABAQUS software to establish the milling model the improved Lagrange method is used to mesh the part and the cutting tool. As shown in Figure II, during the process of mesh dividing part the mesh that will be milled is refining, and the other is coarsening.

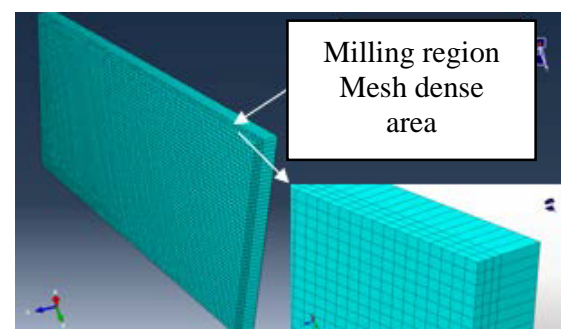

FIGURE II. IMPROVED LAGRANGE MESH DIVISION

\section{Boundary Conditions and Load of Milling Force}

Aiming at rectangular thin-wall parts, in the actual milling process the fixture of part mostly adopts that the bottom of the part is fixed on the milling machine table, two sides of the part and the upper of the part are in a free state. The milling cutter rotates with the spindle and the part does horizontal feed motion with the table. In order to ensure the validity and accuracy of machining deformation simulation, combined with actual movement of the milling process it adopts that the bottom of the part is added fixed constraints and other end surfaces have no constraints when adding boundary conditions. When the milling cutter is cutting to a part of the workpiece, the milling process is realized by the spiral movement of the cutter teeth. Because of high-speed rotating of the cutter with the spindle in this paper it takes milling force to load the end of the workpiece cutting and moved according to the feed speed until the cutting end of the workpiece. Simulation of milling process is carried out by this process. The size of the load is applied to the milling force data measured in the milling experiments.

\section{Finite ELEMENT SimUlation Data ANALYSIS OF THIN-WALlED PARTS MACHINING DEFORMATION}

\section{A. Actual Working Condition}

According to the above analysis, the finite element analysis of the workpiece is carried out by ABAQUS finite element software. And the simulation parameters are shown in Table I.

TABLE I. SIMULATION PROCESSING PARAMETERS

\begin{tabular}{|c|c|c|c|}
\hline number & $\begin{array}{c}\text { Feeding } \\
\text { rate[mm/min] }\end{array}$ & $\begin{array}{c}\text { Milling } \\
\text { depth[mm] }\end{array}$ & $\begin{array}{c}\text { Milling } \\
\text { width[mm] }\end{array}$ \\
\hline 1 & 80 & 0.05 & 15 \\
\hline 2 & 120 & 0.05 & 15 \\
\hline 3 & 160 & 0.05 & 15 \\
\hline 4 & 200 & 0.05 & 15 \\
\hline 5 & 120 & 0.10 & 15 \\
\hline 6 & 120 & 0.15 & 15 \\
\hline 7 & 120 & 0.2 & 15 \\
\hline 8 & 120 & 0.2 & 20 \\
\hline 9 & 120 & 0.2 & 25 \\
\hline 10 & 120 & 0.2 & 30 \\
\hline
\end{tabular}

\section{B. Workpiece Coordinate System Setting}

In order to facilitate the subsequent calculation and analysis, the direction of the coordinate system is shown in Figure IV X is the direction of the cutter feed. $\mathrm{Z}$ is the direction that the cutter is far from the workpiece. Determine the direction of $\mathrm{Y}$ axis by $\mathrm{X}$ and $\mathrm{Z}$ that determined according to the right-hand rule. Refer to the origin rule in figure III ( $O$ is the origin of coordinates). $\mathrm{AB}$ is denoted as $\mathrm{Z}=30 \mathrm{~mm}$ and abbreviated as $\mathrm{Z} 30$, so the BC is abbreviated as $\mathrm{X} 100$.

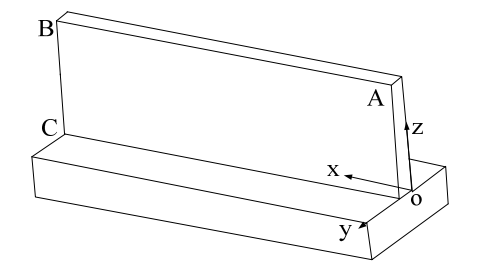

FIGURE III. WORKPIECE MEASUREMENT

\section{Simulation Data Acquisition and Analysis}

As is shown in figure IV. Milling depth is $0.05 \mathrm{~mm}$ and milling width is $15 \mathrm{~mm}$. At this time it simulated to obtain the $\mathrm{XY}$ curve when the feeding rate is $80 \mathrm{~mm} / \mathrm{min}, 120 \mathrm{~mm} / \mathrm{min}$, $160 \mathrm{~mm} / \mathrm{min}$ and $200 \mathrm{~mm} / \mathrm{min}$.

From Figure IV we can see: When the feed rate increased from $80 \mathrm{~mm} / \mathrm{min}$ to $120 \mathrm{~mm} / \mathrm{min}$, the workpiece machining deformation increased $22 \%$. When the feed rate increased from $160 \mathrm{~mm} /$ to $\min 120 \mathrm{~mm} / \mathrm{min}$, the machining deformation of each point increased $26 \%$ approximately. And the increasement of each point is very small. When the feed rate increased from $200 \mathrm{~mm} / \mathrm{min}$ to $160 \mathrm{~mm} / \mathrm{min}$, the deformation of each point increased 34\% approximately. When the feed rate increased, the machining deformation of the workpiece becomes larger.

As is shown in figure V. Feeding rate is $120 \mathrm{~mm} / \mathrm{min}$ and milling width is $15 \mathrm{~mm}$. At this time it simulated to obtain the 
$\mathrm{XY}$ curve when the milling depth is $0.05 \mathrm{~mm}, 0.10 \mathrm{~mm}$, $0.15 \mathrm{~mm}$ and $0.20 \mathrm{~mm}$.

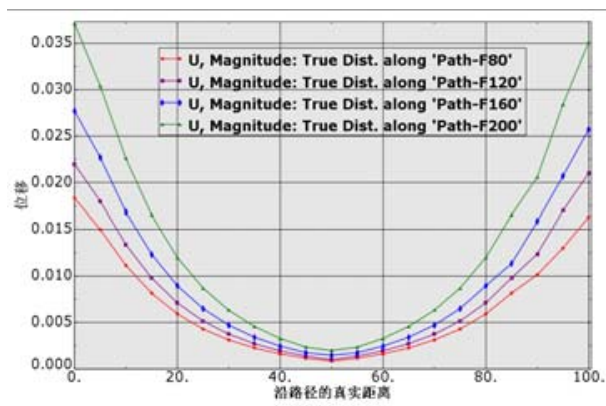

FIGURE IV. INFLUENCE OF FEEDRATE ON THE MACHINING DEFORMATION

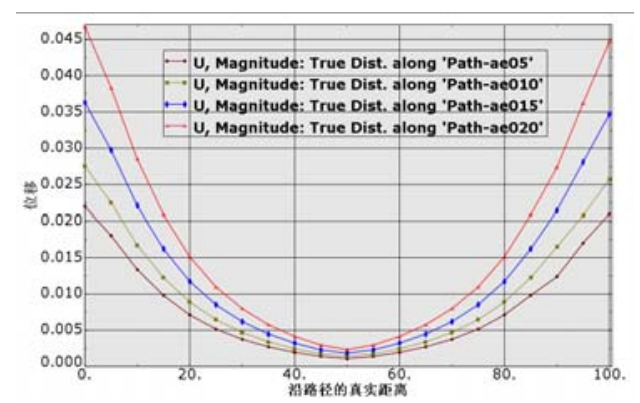

FIGURE V. INFLUENCE OF MILLING DEPTH ON THE MACHINING DEFORMATION

From Figure $\mathrm{V}$ we can see: When the milling depth increased from $0.05 \mathrm{~mm}$ to $0.10 \mathrm{~mm}$ the workpiece machining deformation increased 26\% approximately. And the difference of each point is very small. When the milling depth increased from $0.10 \mathrm{~mm}$ to $0.15 \mathrm{~mm}$ the machining deformation of each point increased 31\% approximately. When the milling depth increased from $0.15 \mathrm{~mm}$ to $0.20 \mathrm{~mm}$ the machining deformation of at each point increased $28 \%$ approximately. With the increase of the depth of the milling the machining deformation is gradually increasing, but the trend is slowing down.

As is shown in figure VI Feeding rate is $120 \mathrm{~mm} / \mathrm{min}$ and milling depth is $0.05 \mathrm{~mm}$. At this time it simulated to obtain the $\mathrm{XY}$ curve when the milling width is $15 \mathrm{~mm}, 20 \mathrm{~mm}, 25 \mathrm{~mm}$ and $30 \mathrm{~mm}$.

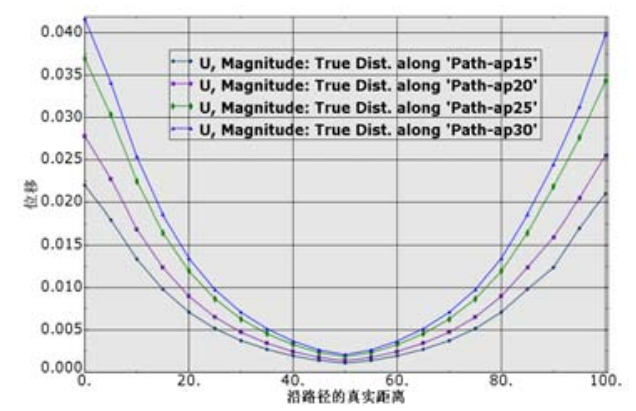

FIGURE VI. INFLUENCE OF MILLING WIDTH ON THE MACHINING DEFORMATION

From Figure VI we can see: When the milling width increased from $15 \mathrm{~mm}$ to $20 \mathrm{~mm}$ the direction $\mathrm{Y}$ of the workpiece deformation increased 27\% approximately. When the milling width increased from $20 \mathrm{~mm}$ to $25 \mathrm{~mm}$ the direction $\mathrm{Y}$ of the workpiece deformation increased $32 \%$ approximately. When the milling width increased from $25 \mathrm{~mm}$ to $30 \mathrm{~mm}$ the direction Y of the workpiece deformation increased 25\% approximately. With the increase of the depth of the milling the machining deformation is gradually increasing, but the trend is slowing down. when the milling width increases the deformation of the workpiece can be increased obviously. But the deformation of the workpiece is slowing down.

\section{EXPERIMENTAL VERIFICATION}

Experiment has been done in XH714 NC machining center by dry milling, reverse milling method. Workpiece material is $45 \#$ steel. The size of thin-walled part is the same as the model of finite element simulation, that is, $\mathrm{L}=100 \mathrm{~mm}$, high $\mathrm{H}=30 \mathrm{~mm}$, wall thickness $\mathrm{W}=5 \mathrm{~mm}$. Cutting tool material is hard alloy and the diameter is $16 \mathrm{~mm}$. The feed rate, milling depth and width are changed in turn. The specific parameters are shown in Table II:

TABLE II. MAIN CUTTING PARAMETERS IN EACH GROUP

\begin{tabular}{|c|c|c|c|}
\hline group & $\begin{array}{c}\text { Feeding } \\
\text { rate[mm/min] }\end{array}$ & $\begin{array}{c}\text { Milling } \\
\text { depth[mm] }\end{array}$ & $\begin{array}{c}\text { Milling } \\
\text { width[mm] }\end{array}$ \\
\hline 1 & 80 & 0.05 & 15 \\
\hline 2 & 120 & 0.10 & 20 \\
\hline 3 & 160 & 0.15 & 25 \\
\hline 4 & 200 & 0.20 & 30 \\
\hline
\end{tabular}

The actual process of the workpiece is shown in Figure VII. After the processing the path of the measured deformation value is compared in the simulation. Use the dial gauge to measure the thickness and the measure distance is $5 \mathrm{~mm}$. The actual wall thickness value subtracts the theoretical wall thickness to get experiment value of the workpiece deformation.

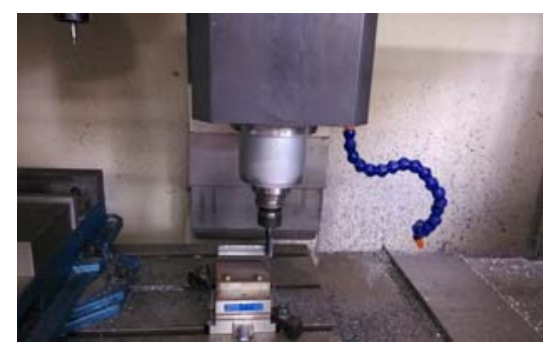

FIGURE VII. ACTUAL MACHINING PROCESS

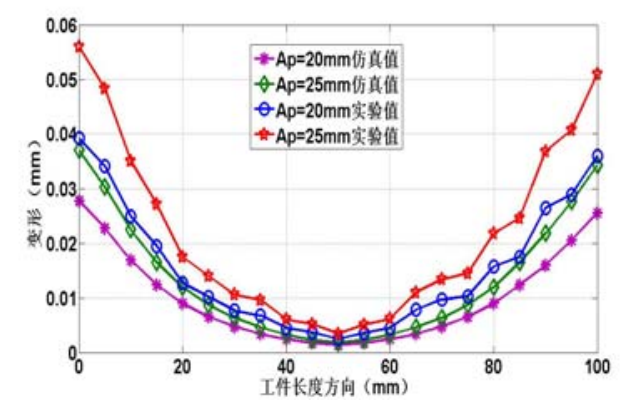

FIGURE VIII. COMPARISON OF MACHINING DEFORMATION OF DIFFERENT MILLING WIDTH 
Figure VIII is to obtain the machining deformation contrast of the different milling width when the milling width is $25 \mathrm{~mm}$ and $20 \mathrm{~mm}$ respectively.

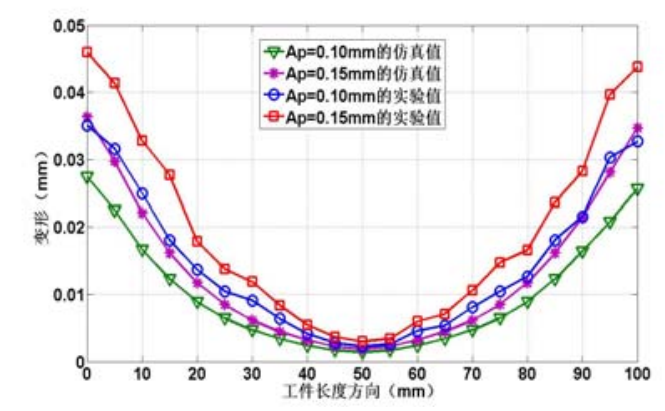

FIGURE IX. COMPARISON OF MACHINING DEFORMATION OF DIFFERENT MILLING DEPTH

Figure IX is to obtain the machining deformation contrast of the different milling depdth when the milling depth is $25 \mathrm{~mm}$ and $20 \mathrm{~mm}$ respectively.

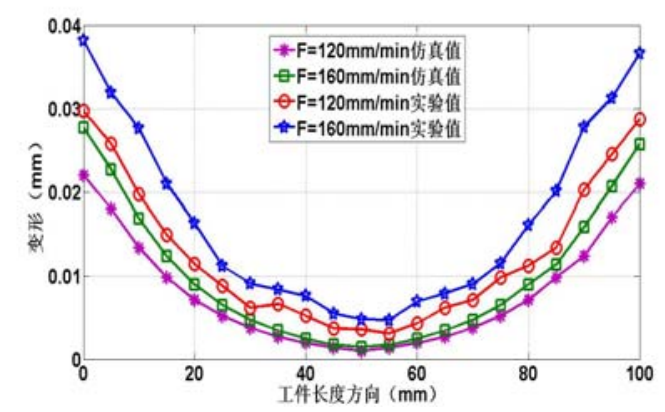

\section{FIGURE X. COMPARISON OF MACHINING DEFORMATION OF DIFFERENT FEEDING RATE}

Figure $\mathrm{X}$ is to obtain the machining deformation contrast of different feeding rate the when the feeding rate is $120 \mathrm{~mm} / \mathrm{min}$ and $160 \mathrm{~mm} / \mathrm{min}$ respectively.

Through the comparison between the experimental values and the simulation results of different cutting parameters we can see that the change trend of experimental values and simulation values are the same. The simulation results are reliable and can be used as the basis for machining deformation prediction and optimization of milling parameters.

\section{CONCLUSION}

- Establish the finite element simulation model of machining deformation of rectangular thin-walled parts in the finite element software ABAQUS.

- Through the finite element prediction model the machining deformation is predicted. Obtain the influence law of different milling parameters on the machining deformation of the workpiece by adjusting the parameters.

- Establish the milling experiments that the conditions are the same as finite element simulation. The experimental values of workpiece deformation and the predicted values of finite element simulation are compared and analyzed. The results show that the experimental values and the predicted values have the same trend. This indicats that the established finite element model is reliable. It provides the theoretical basis for the selection and optimization of thin-walled parts milling parameters of actual milling process.

\section{ACKNOWLEDGEMENT}

This research work was supported by the Nature Science Foundation of Jilin Province, and the project name is "Research on the Predict Technology and Analysis of machining Deformation for Thin-Walled”, no. 20140101086JC.

\section{REFERENCES}

[1] Tan Yun. Study on Deformation Error Prediction of High Speed Machining of Thin-walled Parts of Aluminum Alloy. [D] Harbin Institute of Technology,2008. (In Chinese)

[2] Bi Yunbo, Ke Yinglin and Dong Huiyue. Finite Element Simulation and Analysis of Machining Deformation of Aeronautical Aluminum Alloy Thin-walled Parts[J]. Journal of Zhejiang University (Engineering Edition), 2008,03:397-402. (In Chinese)

[3] Wu Hongbing, Ke Yinglin, Liu Gang and Dong Huiyue. Research on Milling Deformation of Whole Structure of Aviation Frame[J]. Journal of Zhejiang University (Engineering Edition), 2009,03:546-550. (In Chinese)

[4] Huang Zhigang, Ke Yinglin, Wang Litao and $\mathrm{Xu}$ De. Research on Milling Deformation Prediction Based on Orthogonal Cutting Simulation[J]. Journal of Mechanical Engineering, 2004,11:117-122. (In Chinese)

[5] Qin Guohua, Zhang Yunjian and Ye Haichao. Prediction Method of Machining Deformation of Thin-walled Parts Based on Neural Network[J]. Acta Armaentarii, 2013,07:840-845. (In Chinese)

[6] Li Yuanyuan. Study on FE Simulation of Chip Formation and Temperature Field during High Speed Machining Hardened Steel[M]. Dalian: Dalian University of Technology, 2008. (In Chinese)

[7] Kug Weon Kim and Hyo-Chol Sin. Finite Element Method and Thermo-Viseoplastic Cutting Model in Manufacture System [M]. Tokyo, Japan: CRC Press LLC, 2001. 